\title{
Analgesia for acute gingivostomatitis: a national survey of pediatric emergency physicians
}

\author{
Joe MacLellan, $\mathrm{MD}^{* *}$; Samina Ali, $\mathrm{MDCM}^{*^{\dagger}}$; Sarah Curtis, $\mathrm{MD}^{*^{\dagger}}$; Jason Baserman, $\mathrm{MD}^{\S \uparrow}$; \\ Andrew Dixon, $\mathrm{MD}^{*}{ }^{\dagger}$
}

\section{ABSTRACT}

Objectives: Gingivostomatitis is a common, painful pediatric presentation, and yet, few studies are available to guide management. We aimed to describe pediatric emergency physicians' current practice patterns, with respect to analgesic use in children with acute gingivostomatitis, in order to inform future studies.

Methods: A national survey was conducted at all 15 national academic pediatric centres.Electronic surveys were distributed to pediatric emergency physicians using a modified Dillman protocol; non-respondents received paper surveys via post. Data were collected regarding demographic characteristics, clinical behaviour, factors that may influence practice, and future directions.

Results: Response rate was 74\% (150/202). Most physicians $(72 \%)$ preferred the combination of acetaminophen and ibuprofen to either agent alone (ibuprofen 19\%, acetaminophen $7 \%$ ). The preferred second-line analgesics were oral morphine $(48 \%, 72 / 150)$ and compounded topical formulas (42\%, 64/150). The most commonly cited compounded agent was Benadryl plus Maalox (23\%, 35/150). Clinical experience with a medication had the greatest influence on practice pattern, with $52 \%$ (78/149) strongly agreeing. The most commonly cited barrier to adequate analgesia was difficulty in the administration of topical or oral medication to children.

Conclusions: As with many other painful conditions, the combination of acetaminophen and ibuprofen was preferred, followed by either agent alone. Oral morphine and topical compounded agents were also frequently prescribed. Regardless of patient age, physicians preferred oral morphine as a secondline agent to treat pain from severe gingivostomatitis. Future research will focus on determining which analgesic and route (oral or topical) is the most effective and best-tolerated choice.

\section{RÉSUMÉ}

Objectif: La gingivostomatite est une affection douloureuse et fréquente chez les enfants, mais il existe peu d'études sur la prise en charge. Les auteurs, par l'enquête, visaient à faire état des pratiques actuelles parmi les médecins d'urgence pédiatrique en ce qui concerne l'utilisation des analgésiques chez les enfants souffrant d'une gingivostomatite aiguë, dans le but de donner une orientation à des études futures.

Méthode: II s'agit d'une enquête nationale, menée dans les 15 centres pédiatriques d'enseignement au pays. Les questionnaires en version électronique ont été envoyés aux médecins d'urgence pédiatrique selon une version modifiée de la méthode de Dillman; les non-répondants ont reçu un autre questionnaire, cette fois, par la poste, en version imprimée. II y a eu collecte de données sur des caractéristiques démographiques, des habitudes cliniques, des facteurs susceptibles d'influer sur la pratique et des orientations futures.

Résultats: Le taux de réponse s'est élevé à 74\% (150/202). La plupart des médecins préféraient l'association d'acétaminophène et d'ibuprofène (72\%) à l'utilisation seule de l'un ou l'autre de ces médicaments (ibuprofène : 19\%; acétaminophène : $7 \%$ ). Les analgésiques de deuxième intention utilisés le plus souvent étaient la morphine par voie orale $148 \%$ : $72 / 150$ ) et les composés topiques (42\%:64/150). Le mélange mentionné le plus souvent était constitué de Benadryl et de Maalox (23\% : 35/150). Le facteur qui influait le plus sur la pratique était l'expérience clinique d'un médicament; en effet, $52 \%(78 / 149)$ des participants se sont dits " tout à fait d'accord " sur l'énoncé. Enfin, le plus grand obstacle à une analgésie suffisante était la difficulté d'administration des médicaments topiques ou oraux aux enfants.

Conclusions: Comme dans bien d'autres affections douloureuses, l'association d'acétaminophène et d'ibuprofène était la formule préférée, suivie de l'utilisation seule de l'un ou l'autre de ces médicaments. Étaient souvent prescrits aussi la morphine par voie orale et les composés topiques. Indépendamment de l'âge, les médecins préféraient la morphine par voie orale comme médicament de deuxième intention pour traiter la douleur causée par une gingivostomatite importante. Enfin, les futurs travaux de recherche devraient porter sur l'analgésique le plus efficace et la meilleure voie d'administration (orale ou topique) ainsi que sur la formule la mieux tolérée.

Keywords: analgesia, pain, gingivostomatitis, children, emergency

From the *Department of Pediatrics; †Women and Children's Health Research Institute, University of Alberta, Edmonton, AB; $¥ D e p a r t m e n t ~ o f$ Emergency Medicine; §Department of Pediatrics; and ॠCumming School of Medicine, University of Calgary, Calgary, AB.

Correspondence to: Dr. Samina Ali, Department of Pediatrics, Edmonton Clinic Health Academy, 11405 - 87 Avenue, Edmonton, AB T6G 1C9; Email: sali@ualberta.ca 


\section{INTRODUCTION}

Painful oral mucosal lesions are frequently encountered in childhood. ${ }^{1-3}$ Most of those affected have a self-limited viral infection, ${ }^{4}$ and management is usually supportive. There is some limited evidence for the use of anti-viral agents $^{5,6}$; however, this does not address children's acute pain needs. As per current literature, the vast majority of children with acute gingivostomatitis are discharged home with advice regarding hydration, criteria for return to medical care, and pain management. ${ }^{1,7-9}$ Analgesia is an essential component of therapy for gingivostomatitis with added benefits that go beyond short-term patient comfort. For example, studies suggest that patients seeking antibiotics may in fact simply want treatment for pain, ${ }^{10}$ analgesic use has been associated with higher parental satisfaction, ${ }^{11}$ and properly treated oral pain can lead to increased fluid intake, and may decrease acute care visits or hospitalization. ${ }^{12}$

Acetaminophen and ibuprofen are considered first-line analgesic agents for most mild-moderate pain. ${ }^{13}$ Warm salt-water gargles, oral rinses, sprays, viscous lidocaine, and lozenges have been used as over-the-counter (OTC) alternatives, when these first-line agents are not adequate. ${ }^{4,14,15}$ Other options may include oral opioids or a combination of prescription and/or OTC medicines to form a mouthwash preparation. ${ }^{1,3,9}$ Our study's objective was to describe the current national practice pattern and attitudes of pediatric emergency physicians with respect to analgesic use in children with gingivostomatitis, in order to inform future randomized trials.

\section{METHODS}

\section{Study design, setting, and population}

A descriptive cross-sectional survey was conducted from October 2013 to March 2014. Research ethics approval was obtained from the University of Alberta. This national survey was administered to all pediatric emergency physicians in the Pediatric Emergency Research Canada (PERC) database. At the time of this study, the PERC network included all 15 pediatric teaching hospitals across Canada, with a total of 204 physician members.

\section{Survey protocol}

This study followed recommended methodological guidelines for self-administered clinician surveys. ${ }^{16}$
Survey items were created through literature review and evaluated by an expert panel composed of five individuals, including pain researchers, pediatric emergency physicians, and survey methodology experts. Electronic surveys were distributed and managed by an arms-length data management group at the University of Alberta. Study data were collected and managed using the REDCap electronic data capture tool, a secure, Web-based application designed to support data capture for research studies. ${ }^{17}$ Survey distribution followed a modified Dillman protocol. ${ }^{18}$ On day 0, a letter of introduction was emailed to eligible participants. On day 7 , an electronic survey was emailed. On day 21, the e-survey was re-sent to non-respondents. Contact information for non-respondents was provided to a research assistant. On day 35, a final paper survey was posted to non-respondents. These paper surveys were devoid of identifying information and returned in self-addressed envelopes. Consent to participation in the study was implicit upon completion of the survey. Any and all questions could be skipped, at the respondent's will. Survey data were presented to the study team in an anonymized, aggregate form.

\section{Study measurements}

A 25-item survey was designed following item generation, item reduction, pre-testing, pilot testing, and clinical sensibility testing. ${ }^{16,19}$ We collected variables related to demographic characteristics (e.g., age, sex, years of experience), clinical behaviours (e.g., preferred analgesics, frequency of analgesic use), factors that may influence practice (perceived barriers and facilitators to analgesic use), and future directions for research.

Four clinical vignettes with varying patient age (10-month-old or 12-year-old) and severity (mild or severe) were used. One specific mouthwash (Akabutu's) was included due to its familiarity to local investigators. Like many mouthwash recipes, Akabutu's contains saline, hydrocortisone, nystatin, lidocaine, and glycerin.

\section{Hypothesis}

We hypothesized that the majority of physicians would recommend simple analgesics, such as acetaminophen and ibuprofen, as well as compounded formulations. Use of other medications were thought to be related to various clinician demographic characteristics. 


\section{Data analysis}

Univariate summaries (means, weighted means, medians, standard deviations, ranges) were provided for continuous variables (e.g., age), and frequencies and percentages were used to summarize categorical variables (e.g., sex). Chi-square tests were used to test the significance of categorical variables. Multipleresponse analysis was used wherever respondents were allowed to choose more than one response for a single question. $P$-values less than 0.05 were considered statistically significant. Analysis was performed using IBM SPSS (Version 22) in consultation with the Biostatistics Consultant Group at University of Alberta.

\section{RESULTS}

\section{Demographic characteristics of survey respondents}

One hundred fifty physicians completed the survey, leading to a response rate of $74 \%(150 / 202)$ (Figure 1). Table 1 shows demographic characteristics of the respondents.

\section{Clinical behaviour}

Physicians preferred to use both acetaminophen and ibuprofen concurrently $(72 \%, 108 / 150)$ for the first-line treatment of pain related to acute gingivostomatitis, as compared to ibuprofen alone (19\%, 29/150), acetaminophen alone $(7 \%, 11 / 150)$, or neither agent $(1 \%, 2 / 150)(p<0.0001)$. Further, this preference did

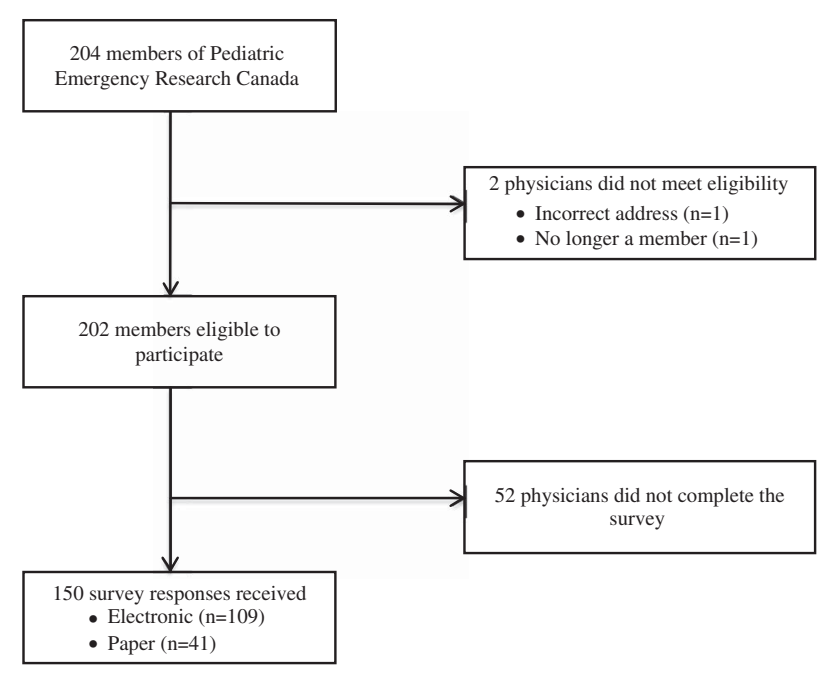

Figure 1. Flow diagram. not vary with the highest level of training $(p=0.713)$, experience $(<6$ years, $6-10$ years, $>10$ years $)$ $(p=0.193)$, or percentage of job spent in pediatric emergency medicine (PEM) (<25\%, 26\%-50\%, $51 \%-75 \%, 76 \%-100 \%)(p=0.571)$. Among those who indicated they preferred to use ibuprofen and acetaminophen concurrently, 90\% (83/99) chose ibuprofen when asked to pick their one preferred first-line agent.

Sixty-three percent $(92 / 147, p=0.002)$ of respondents reported that they had not recommended any other OTC analgesia other than acetaminophen and/or ibuprofen for gingivostomatitis in the prior year. Just over $50 \%(73 / 144)$ of respondents indicated that they had provided compounded medicine (i.e., Akabutu's mouthwash, Benadryl plus Maalox, Benadryl/Maalox/ Lidocaine) for gingivostomatitis in the last year; $49 \%(67 / 138)$ reported that they had provided prescription analgesia (i.e., Naproxen, oral steroid, oral opioids). No physicians reported offering complementary and alternative therapies.

PEM-trained physicians and those working greater than $75 \%$ PEM used prescription analgesia more often than other physicians $(p=0.044$ and $p=0.021$, respectively). The amount of time spent working in PEM influenced

\begin{tabular}{|c|c|}
\hline Characteristic & Number (\%, if applicable) \\
\hline Age (years) $(n=147)$ & $42.97+/-8.56$ \\
\hline Sex (male) & $70(47)$ \\
\hline \multicolumn{2}{|l|}{ Highest level of training } \\
\hline PEM fellowship & $70(46.7)$ \\
\hline FRCPC pediatrics & $43(28.7)$ \\
\hline FRCPC emergency & $24(16)$ \\
\hline CCFP-EM & $11(7.3)$ \\
\hline Other* & $2(1.3)$ \\
\hline Attending physician experience (years) & $12.04+/-8.37$ \\
\hline \multicolumn{2}{|l|}{ Percentage of job that is PEM } \\
\hline $0 \%-25 \%$ & $14(9.3)$ \\
\hline $26 \%-50 \%$ & $23(15.3)$ \\
\hline $51 \%-75 \%$ & $17(11.3)$ \\
\hline $76 \%-100 \%$ & $96(64)$ \\
\hline \multicolumn{2}{|l|}{ Language of response } \\
\hline English & $139(92.7)$ \\
\hline French & $11(7.3)$ \\
\hline Number of PEM shifts per month & $8.70+/-3.69$ \\
\hline
\end{tabular}


the reported provision of compounded medicine, with those working greater than $75 \%$ being less likely to provide a compounded medicine $(p=0.010)$.

Figure 2 outlines the top five preferred analgesic recommendations for acute gingivostomatitis. Respondents with Royal College of Physicians \& Surgeons (Canada) certification in pediatrics and those working less than 25\% PEM preferred ibuprofen, acetaminophen, and oral morphine, but chose lidocaine more frequently than compounded preparations. The most commonly preferred $(55 \%, 35 / 64)$ compounded analgesic agent was a Benadryl (diphenhydramine) plus Maalox (magnesium hydroxide/aluminum hydroxide/simethicone) combination. Other notable compounded formulas included Akabutu's mouthwash $(28 \%, 18 / 64)$, viscous lidocaine in Kool-Aid (6\%, 4/64), "magic mouthwash" (5\%, 3/64), lidocaine/antacid $(3 \%, 2 / 64)$, Seattle mouthwash $(2 \%$, $1 / 64)$, and a locally compounded formulation (2\%, 1/64).

In the setting of mild gingivostomatitis, after appropriate dosing of acetaminophen and ibuprofen, the number one ranked treatment choice was "no further treatment" for both a 10-month-old infant (28\%, 33/116) and a 12 -year-old adolescent $(26 \%, 29 / 113)$. Those who did treat further chose Benadryl plus Maalox as their number one ranked choice for both a 10-month-old $(22 \%, 26 / 116)$ and a 12 -year-old $(21 \%, 24 / 113)$.

In the setting of severe gingivostomatitis, after appropriate dosing of acetaminophen and ibuprofen, the number one ranked treatment choice by responding

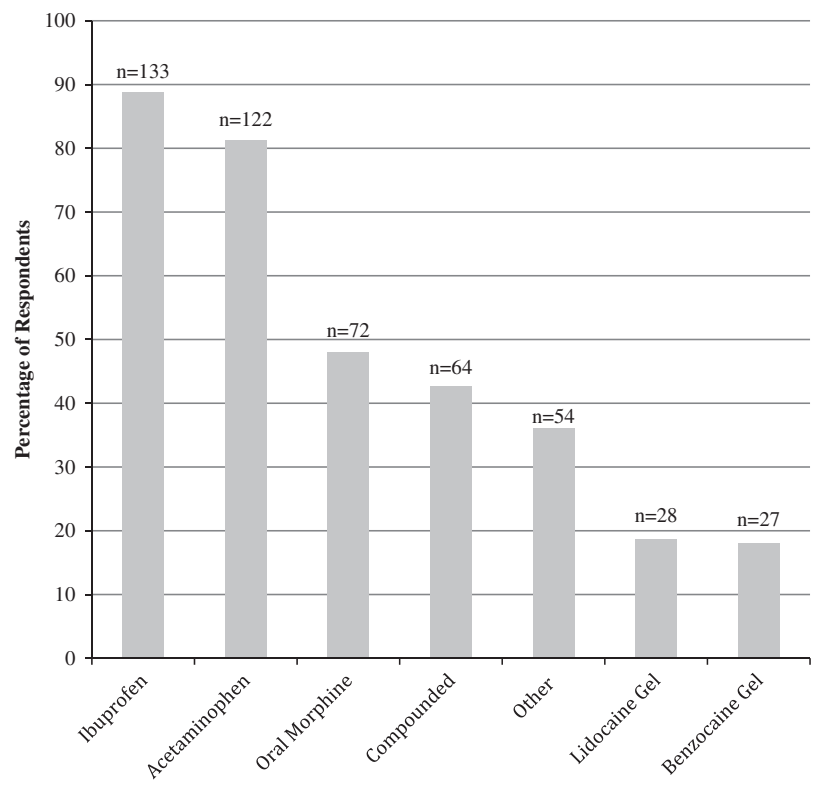

Figure 2. Top five preferred analgesics for acute gingivostomatitis $(n=150)$. physicians was oral morphine for both a 10-month-old infant $(43 \%, 51 / 118)$ and a 12-year-old adolescent (44\%, 52/118). Further, the majority of respondents $(88 \%, 132 / 150)$ did not alter their practice on discharge. Among those who did, the most commonly cited advice was using cold foods as analgesia (24\%, 4/17) and avoiding painful food/drink (29\%, 5/17).

\section{Factors that may influence practice}

Table 2 depicts what respondents reported as influencing their choice of analgesia for acute gingivostomatitis. A significant proportion of respondents indicated that they did not know what the best evidence was for analgesia in acute gingivostomatitis $(34 \%, 45 / 148)$ and those who knew the evidence $(61 \%, 63 / 103)$ felt that it was either "very weak" or "somewhat weak."

The most commonly reported barrier to optimal pain management was the difficulty of administration of oral medication to children $(15 \%, 13 / 84)$. Other barriers are described in Table 3.

\section{Future directions}

In order to help with the design of future trials, respondents were asked what percent difference between study drugs would be clinically significant. Figure 3 depicts the respondent agreement for a variety of trial designs.

\begin{tabular}{|c|c|}
\hline Barrier & $\begin{array}{l}\% \text { Agreement (number } \\
\text { of respondents) }\end{array}$ \\
\hline Difficult to administer topical/oral analgesia & $15.5(13)$ \\
\hline Lack of effective medications/options & $14.3(12)$ \\
\hline $\begin{array}{l}\text { Uncomfortable with opioid use (parent } \\
\text { or practitioner) }\end{array}$ & $13.1(11)$ \\
\hline $\begin{array}{l}\text { Desired medication unavailable or access } \\
\text { difficult }\end{array}$ & $11.9(10)$ \\
\hline Side effects & $10.7(9)$ \\
\hline Lack of or conflicting evidence & $8.3(7)$ \\
\hline $\begin{array}{l}\text { Parents' inability and/or unwillingness to } \\
\text { follow instructions }\end{array}$ & $8.3(7)$ \\
\hline Physician lack of knowledge & $6.0(5)$ \\
\hline Lack of follow-up & $4.8(4)$ \\
\hline Time & $4.8 \%(4)$ \\
\hline Other ${ }^{*}{ }^{\dagger}$ & $26.2 \%(22)$ \\
\hline
\end{tabular}




\begin{tabular}{lc|}
$\begin{array}{l}\text { Table 3. Factors affecting analgesic choice }(\boldsymbol{n}=\mathbf{1 4 7} \text {, unless } \\
\text { otherwise stated) }\end{array}$ \\
\hline Factor & $\begin{array}{c}\text { Agreement (number of } \\
\text { respondents) }\end{array}$ \\
\hline Clinical experience $(n=149)$ & $97(144)$ \\
Literature & $65(96)$ \\
Practice guidelines & $46(67)$ \\
Local practice $(n=149)$ & $83(123)$ \\
Side effects & $95(140)$ \\
Negative consequences of pain & $90(133)$ \\
Personal experience $(n=146)$ & $50(73)$
\end{tabular}

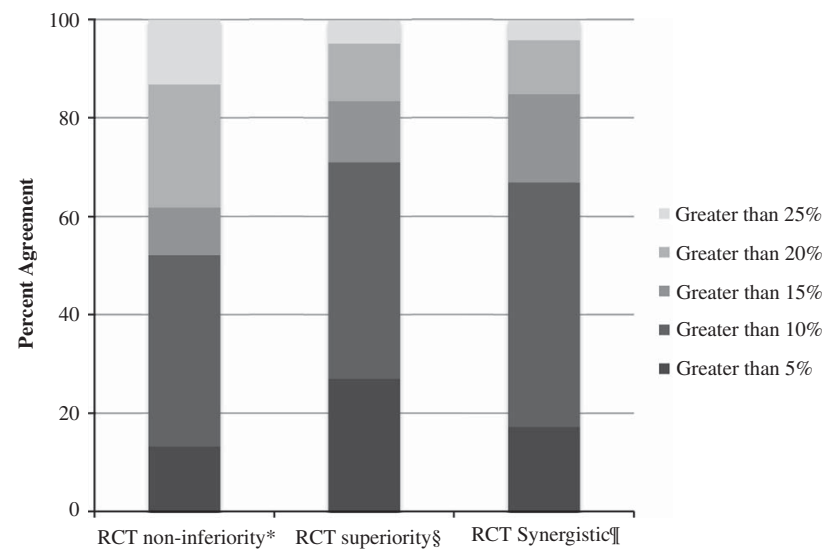

Figure 3. Difference between a study drug and respondent's first-line treatment deemed clinically significant.

* non-inferior in efficacy, difference in palatability and ease of administration, $n=144$.

$\S$ superior in efficacy, same cost, ease of administration, and side effects, $n=145$.

I synergistic in efficacy, $n=145$.

\section{DISCUSSION}

Despite a paucity of direct evidence for use in acute gingivostomatitis, a majority of respondents indicated that they used ibuprofen and acetaminophen concurrently as a first-line treatment. To date, there is limited but promising evidence to support the practice of combining acetaminophen and ibuprofen for pain treatment in children. ${ }^{20-24}$ As noted by others, there remains a need for large-scale studies on both the efficacy and safety of this combination for the treatment of pain. ${ }^{20}$

When asked to choose their preferred oral analgesic, respondents showed a strong preference for ibuprofen over acetaminophen. Despite the likely benefit of ibuprofen's anti-inflammatory effect, there is no direct comparison of ibuprofen and acetaminophen's analgesic efficacy in acute gingivostomatitis. Still, there is mounting evidence that ibuprofen has equal or better analgesic properties for a variety of other indications in children. $^{25,26}$ As such, ibuprofen may be the best first choice for simple oral analgesia in the treatment of acute gingivostomatitis, but direct evidence is lacking.

Almost half of our survey respondents selected oral morphine as one of their top five analgesic preferences, second to only acetaminophen and ibuprofen overall. This is likely a reflection of a physician's desire to identify a suitable alternative to codeine (which has been removed from virtually all Canadian pediatric hospital formularies) combined with fears regarding oxycodone addiction potential. ${ }^{27}$ Currently, there is no evidence to suggest that any one agent is the better opioid for children, highlighting a need for a well-designed, large, multicentre trial of oral opioids for acute pediatric pain.

When presented with the vignette of a patient with severe gingivostomatitis (with inadequate response to combination acetaminophen and ibuprofen), respondents ranked oral morphine as their number one choice regardless of patient age. This suggests that the majority of respondents were comfortable providing opioids to both small children and adolescents. This is in contrast to previous studies that have shown that decreasing age was correlated with a decrease in reported treatment with opioids. $^{28}$ The majority of our respondents had subspecialty training in PEM or specialty training in pediatrics, and it is possible that more experience with the treatment of children may have led to this greater reported comfort.

Half of respondents indicated that they had prescribed/ provided compounded analgesia within the previous year. Some of these preparations were originally designed for treatment of patients with oral mucositis related to cancer (e.g., Akabutu's mouthwash). Given the dissimilarities in pathophysiology, acute gingivostomatitis will likely be imperfectly treated with an agent intended for cancerrelated mucositis. Among the reported compounded medicines in our study, the most pharmacologically intuitive ingredients to include in a topical compounded agent would include diphenhydramine or lidocaine, for their known analgesic properties. ${ }^{29}$ Such compounded formulas can vary in viscosity, flavour, and volume of administration. The unique properties of each preparation could have a significant impact on palatability, ease of administration, and clinical effectiveness.

To our knowledge, only two randomized controlled trials have been conducted in the treatment of gingivostomatitis. ${ }^{4,5}$ Hopper et al. compared $2 \%$ lidocaine to 
placebo in improving oral intake in children with painful infectious mouth ulcers. No difference was found in fluid intake or the need for rescue medication. ${ }^{4}$ Amir et al. compared oral acyclovir to placebo in berpetic gingivostomatitis and found that, when started within the first 72 hours, acyclovir shortened the duration of feeding and drinking difficulties. ${ }^{5}$ This study did not address other causes of gingivostomatitis. Given the limited number of studies, it remains unclear which option is the optimal choice.

More than half of the physicians surveyed reported at least one barrier to optimal pain management. The most commonly cited barrier was difficulty in administration of topical or oral analgesia to children. Other respondents mentioned lack of effective options and side effects. This suggests that, after clinical effectiveness, important secondary outcomes to consider in future studies would include side effects and ease of administration. Some respondents also disclosed that concern about opioid use, either from the family or the practitioner themselves, was a major barrier to adequate analgesia. This reinforces the need for ongoing education around the safety and efficacy of opioids in children, when used in accordance with the best practice. Finally, a number of respondents listed lack of availability of a desired medication as a barrier to optimal pain management. For example, one popular demulcent agent in many topical preparations (Maalox) has been unavailable in Canada since 2012.

\section{LIMITATIONS}

It is possible that some survey respondents were affected by social desirability bias. We attempted to mitigate this bias by providing the survey to participants through an anonymous self-administration platform, and through the use of neutral question style.

No comparison can be made between respondents and non-respondents. Because of this, we cannot be certain that our results were not affected by selfselection. However, this is likely mitigated by our high response rate.

Only $50 \%$ of physicians working in emergency departments in pediatric hospitals are members of PERC. Also, many children are treated in non-pediatric emergency hospitals across Canada. The treatment of gingivostomatitis by these community providers and other pediatric emergency physicians may differ from the behaviours reported in our survey.

\section{CONCLUSIONS}

To our knowledge, this national study is the first to detail analgesic use by pediatric emergency physicians for patients with pain-related to acute gingivostomatitis. As expected, the majority of physicians preferred simple analgesics, such as ibuprofen and acetaminophen, and most frequently used them in combination. The most commonly reported second-line analgesic agents were oral morphine and compounded agents, but practitioners also frequently cited a variety of other agents. The breadth of reported analgesic agents in use demonstrated by this survey highlights the lack of best evidence for the treatment of pain for this condition. This study has provided some direction as to which medications to consider for a trial study, namely oral morphine and a combination of diphenhydramine and antacid suspension. Future studies will also need to carefully consider the many barriers to optimal pain management cited in this study.

Acknowledgements: Drs. Amy Drendel, Hsing Jou, Shawn Dowling, Antonia Stang, and Manu Kundra participated as members of an expert panel who helped with survey tool creation. Drs. Dominic Allain and Vince Grant participated in language editing/translation. Ms. Nadia Dow functioned as the research coordinator for this study. Ms. Melissa Gutland provided administrative support for the implementation of this study. Mr. Sung Hyun Kang assisted with statistical analyses. Dr. Joe MacLellan secured a grant from Women and Children's Health Research Institute to support this work.

Competing interests: None declared.

\section{REFERENCES}

1. Faden H. Management of primary herpetic gingivostomatitis in young children. Pediatr Emerg Care 2006;22(4): 268-9.

2. World Health Organization. A guide to clinical management and public bealth response for band, foot and mouth disease. Geneva, Switzerland: WHO Press; 2011: 1-71.

3. Fleisher GR, Ludwig S. Dental emergencies. In: (eds. Nelson LP, Shusterman S.) Textbook of pediatric emergency medicine, 6th ed. Philadelphia: Lippincott Williams \& Wilkins; 2010, 1538-44.

4. Hopper SM, McCarthy M, Tancharoen C, et al. Topical lidocaine to improve oral intake in children with painful infectious mouth ulcers: a blinded, randomized, placebocontrolled trial. Ann Emerg Med 2014;63(3):292.

5. Amir J, Harel L, Smetana Z, et al. Treatment of herpes simplex gingivostomatitis with aciclovir in children: a randomised double blind placebo controlled study. BMF 1997;314:1800-3. 
6. Nasser $M$, Fedorowicz $Z$, Khoshnevisan $M H$, et al. Acyclovir for treating primary herpetic gingivostomatitis. Cocbrane Database Syst Rev 2008;4:CD006700.

7. National Institute for Health Care Excellence, Clinical Knowledge Summaries. Hand, foot, and mouth disease. Available at: http://cks.nice.org.uk/hand-foot-and-mouthdisease\#!scenario (accessed May 2014).

8. Van Driel ML, De Sutter A, Deveugele M, et al. Are sore throat patients who hope for antibiotics actually asking for pain relief? Ann Fam Med 2006;4(6):494-9.

9. Mell HK. Management of oral and genital herpes in the emergency department. Emerg Med Clin North Am 2008; 26:457-73.

10. Chan L, Russell TJ, Robak N. Parental perception of the adequacy of pain control in their child after discharge from the emergency department. Pediatr Emerg Care 1998;14(4):251-3.

11. Amir J, Harel L, Smetana Z, et al. The natural history of primary herpes simplex type 1 gingivostomatitis in children. Pediatr Dermatol 1999;16:259-63.

12. Myhealth.alberta.ca. Health information and tools. Hand-foot-and-mouth disease; 2015. Available at: https:// myhealth.alberta.ca/health/Pages/conditions.aspx?hwid=ty6230 (accessed May 2014).

13. World Health Organization. Pharmacological treatment strategies, patient-level guidelines for health professionals. WHO guidelines on the pharmacological treatment of persisting pain in children with medical illnesses. Geneva, Switzerland: WHO Press; 2012: 36-53.

14. Hale L, Wojnarowska F. Mouth ulcers: how can you help? Practitioner 1997;241(1571):86-90.

15. Wolfson AB, Hendey GW, Ling LJ, et al. Oral and maxillofacial disorders. In (ed. Kwon M.) Harwood-Nuss' clinical practice of emergency medicine. Philadelphia: Lippincott Williams \& Wilkins; 2012, 375-80.

16. Burns KE, Duffett $M$, Kho ME, et al. A guide for the design and conduct of self-administered surveys of clinicians. CMA7 2008;179(3):245-52.

17. Harris PA, Taylor F, Thielke R, et al. Research electronic data capture (REDCap) - a metadata-driven methodology and workflow process for providing translational research informatics support. 7 Biomed Inform 2009;42(2):377-81.
18. Dillman DA. Mail and telephone surveys: the total design method. New York: John Wiley \& Sons; 1978.

19. Mello M, Merchant R. Surveying emergency medicine. Acad Emerg Med 2013;20(4):409-12.

20. Smith C, Goldman RD. Alternating acetaminophen and ibuprofen for pain in children. Canadian Fam Phys 2012; 58:645-7.

21. Wong T, Stang AS, Ganshorn H, et al. Combined and alternating paracetamol and ibuprofen therapy for febrile children. Cochrane Database Syst Rev 2013;10:CD009572.

22. Mattos JL, Robison JG, Greenberg J, et al. Acetaminophen plus ibuprofen versus opioids for treatment of posttonsillectomy pain in children. Int $\mathcal{F}$ Pediatr Otorbinolaryngol 2014;78(10):1671-6.

23. Gazal G, Mackie IC. Comparison of paracetamol, ibuprofen or their combination for pain relief following extractions in children under general anaesthesia: a randomized controlled trial. Int $\mathcal{F}$ Paediatr Dent 2007;17:169-77.

24. Ong CK, Seymour RA, Lirk P, et al. Combining paracetamol (acetaminophen) with nonsteroidal antiinflammatory drugs: a qualitative systematic review of analgesic efficacy for acute postoperative pain. Anesth Analg 2010;110:1170-9.

25. Pierce CA, Voss B. Efficacy and safety of ibuprofen and acetaminophen in children and adults: a meta-analysis and qualitative review. Ann Pharmacother 2010;44(3):489-506.

26. Clark E, Plint AC, Correll R, et al. A randomized, controlled trial of acetaminophen, ibuprofen, and codeine for acute pain relief in children with musculoskeletal pain. Pediatrics 2007;119(3):460-7.

27. The Globe and Mail. New opioid standards to tackle widespread, serious abuse in Canada; 2014. Available at: http:// www.theglobeandmail.com/life/health-and-fitness/health/newopioid-standards-to-tackle-widespread-serious-abuse-in-canada/ article19486636/ (accessed 3 February 2015).

28. Kircher J, Ali S, Drendel A, et al. Acute pediatric musculoskeletal pain treatment: a North American survey of practice variation [abstract]. CFEM 2012;14(S1):S32.

29. Pavlidakey PG, Brodell BE, Helms SE. Diphenhydramine as an alternative local anesthetic agent. $\mathcal{f}$ Clin Aesthetic Dermatol 2009;2(10):37-40. 